\title{
Performance Characteristics of a Pseudo-Operational Ensemble Kalman Filter
}

\author{
RYAN D. TORN AND GREgORY J. HAKIM
}

University of Washington, Seattle, Washington

(Manuscript received 1 November 2007, in final form 22 February 2008)

\begin{abstract}
The 2-yr performance of a pseudo-operational (real time) limited-area ensemble Kalman filter (EnKF) based on the Weather Research and Forecasting Model is described. This system assimilates conventional observations from surface stations, rawinsondes, the Aircraft Communications Addressing and Reporting System (ACARS), and cloud motion vectors every $6 \mathrm{~h}$ on a domain that includes the eastern North Pacific Ocean and western North America. Ensemble forecasts from this system and deterministic output from operational numerical weather prediction models during this same period are verified against rawinsonde and surface observation data. Relative to operational forecasts, the forecast from the ensemble-mean analysis has slightly larger errors in wind and temperature but smaller errors in moisture, even though satellite radiances are not assimilated by the EnKF. Time-averaged correlations indicate that assimilating ACARS and cloud wind data with flow-dependent error statistics provides corrections to the moisture field in the absence of direct observations of that field. Comparison with a control experiment in which a deterministic forecast is cycled without observation assimilation indicates that the skill in the EnKF's forecasts results from assimilating observations and not from lateral boundary conditions or the model formulation. Furthermore, the ensemble variance is generally in good agreement with the ensemble-mean error and the spread increases monotonically with forecast hour.
\end{abstract}

\section{Introduction}

Ensemble-based data assimilation algorithms, such as the ensemble Kalman filter (EnKF), have gained considerable attention as a method of generating the best estimate of the atmospheric state given output from a numerical weather prediction (NWP) model and imperfect observations. An important aspect of ensemble filters concerns the background-error statistics, which determine the relative weighting for a short-term forecast as compared to observations, and also how observation information affects model state variables. Whereas most existing data assimilation systems assume a quasi-fixed background-error covariance matrix, the EnKF employs a flow-dependent estimate computed from a short-term forecast ensemble. These flow-dependent error statistics are expected to produce an analysis with smaller errors than schemes that em-

Corresponding author address: Ryan Torn, Department of Earth and Atmospheric Sciences, University at Albany, State University of New York, Albany, NY 12222.

E-mail: torn@atmos.albany.edu ploy fixed-error statistics (e.g., Snyder and Hamill 2000; Whitaker et al. 2004). The interested reader is directed to Evensen (2003) or Hamill (2005) for reviews of the EnKF.

Progress on EnKF systems has reached the point where several groups have applied it to global NWP models in operational settings. Houtekamer et al. (2005) used an EnKF to assimilate all available observations with the Canadian Meteorological Center (CMC) Global Environmental Multiscale (GEM) model. Their results show that the error in EnKFinitialized forecasts is similar to those in the CMC operational three-dimensional variations data assimilation (3DVAR) scheme. This favorable performance lead to the operational implementation of the EnKF at CMC in January 2005. Whitaker et al. (2008) and Szunyogh et al. (2008) show that an EnKF applied to the National Centers for Environmental Prediction (NCEP) Global Forecasting System (GFS) gave forecasts with lower errors than the NCEP operational 3DVAR system, especially in data-sparse regions, such as the Southern Hemisphere. Unlike the Houtekamer et al. (2005) experiments, the Whitaker et al. (2008) and Szunyogh et al. (2008) experiments do not consider satellite radi- 

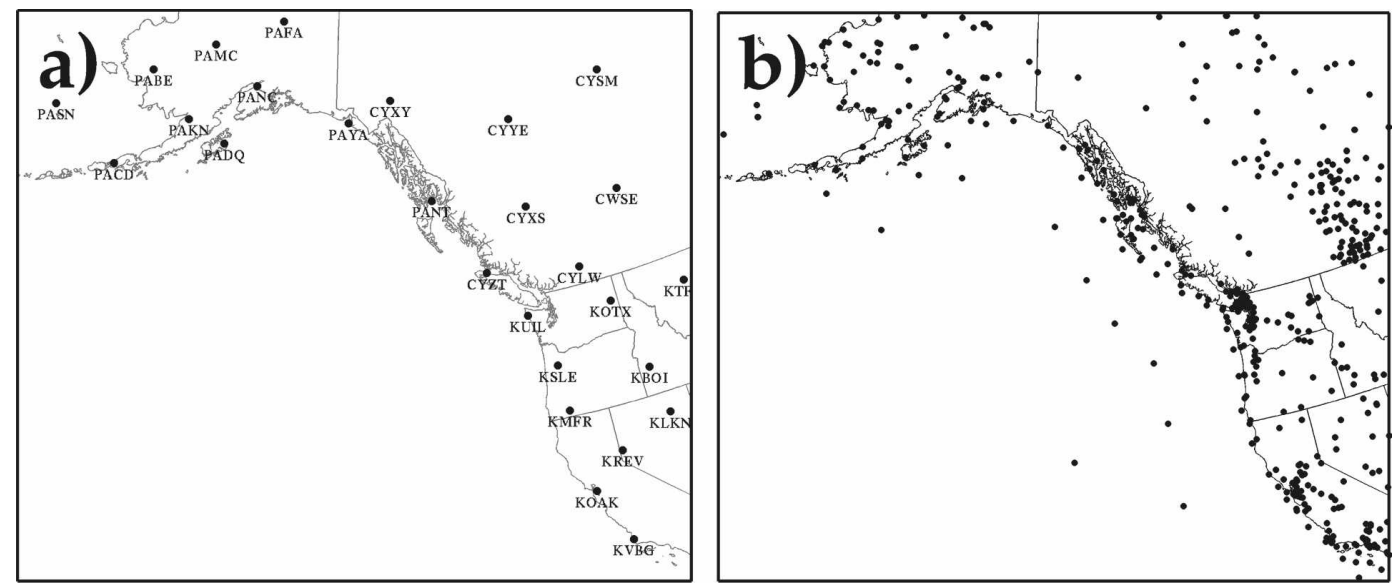

FIG. 1. Distribution of (a) rawinsonde and (b) fixed surface stations assimilated by the UW EnKF system. The observations shown in (a) and (b) are also used to verify the forecasts.

ance data, thus, the observation coverage is less uniform.

Other groups have used an EnKF to assimilate observations at the convective scale, where error statistics are even harder to estimate than at the global scale and can rapidly evolve. Although much of the work at these scales has been performed in a perfect model context, where observations are drawn from a model simulation that is considered "truth" (e.g., Snyder and Zhang 2003; Tong and Xue 2005; Caya et al. 2005), Dowell et al. (2004) were able to capture the location and major features of an isolated convective storm by assimilating actual radar winds with an EnKF.

Although there has been significant effort at implementing an EnKF at both the global and convective scale, relatively less attention has been devoted to the synoptic and mesoscale (e.g., Zhang et al. 2006; Meng and Zhang 2007). One possible reason is the added complication of an appropriate ensemble of lateral boundary conditions for limited-area domains, which are needed to sustain ensemble variance over long time periods. A natural method for populating an ensemble of lateral boundary conditions involves pairing limitedarea ensemble members to a global-model ensemble. Since such ensembles do not always exist or may be of the wrong size, Torn et al. (2006) proposed and tested a series of alternative methods for generating ensemble boundary conditions, which have analysis errors in the domain interior that are comparable to a global ensemble. Dirren et al. (2007) evaluated one of these boundary methods with a realistic distribution of observations in a perfect model scenario on a domain characterized by sparse in situ data and complex topography. Their results indicate that assimilating observations with an EnKF on this domain successfully constrains the error, even for unobserved fields.
This paper extends Dirren et al. (2007) by implementing an EnKF to assimilate real observations on the same limited-area domain in a pseudo-operational setting, in real time, over a 2-yr period. The relative lack of in situ data and complex topography in this region provides a challenging setting for evaluating the EnKF. Furthermore, these results provide proof-of-concept for the viability of cycling a limited-area EnKF for an extended period of time.

This paper is organized as follows. An overview of the model and the observations assimilated is given in section 2. Ensemble variance is evaluated in section 3, while the RMS errors in forecasts initialized from the ensemble-mean analysis are described in section 4 . The relative contribution of the forecast model and lateral boundary conditions to the skill of the EnKF forecasts is described in section 5. A summary and concluding discussion of these results are provided in section 6 .

\section{System setup}

The performance of a pseudo-operational EnKF system, which we shall call the University of Washington EnKF (UW EnKF), is evaluated during the time period 1 January 2005-1 January 2007. This system produces a 90-member analysis ensemble every $6 \mathrm{~h}(0000,0600$, 1200 , and 1800 UTC) in real time, on the domain used by Dirren et al. (2007), which includes the eastern North Pacific Ocean and western North America (Fig. 1). The analysis ensemble is integrated forward using version 2.0.3.1 of the Advanced Research version (ARW) of Weather Research and Forecasting (WRF), a nonhydrostatic primitive equation mesoscale model (Skamarock et al. 2005), on a numerical grid with 45$\mathrm{km}$ horizontal grid spacing and 33 vertical levels. An overview of the technique is provided here, with details supplied in the appendixes. 
TABLE 1. Average number of observations for each observing platform assimilated during each forecast cycle by the UW EnKF system. There are a total of 30 rawinsonde profiles at 0000 and 1200 UTC.

\begin{tabular}{llrrrr}
\hline & & \multicolumn{4}{c}{ Analysis time } \\
\cline { 3 - 6 } & & 0000 & 0600 & 1200 & 1800 \\
Observation & \multicolumn{1}{c}{ Type } & UTC & UTC & UTC & UTC \\
\hline Surface & Altimeter, $u, v$ & 430 & 420 & 420 & 440 \\
Rawinsonde & $u, v, T$, RH & 1000 & 0 & 1000 & 0 \\
ACARS & $u, v, T$ & 1650 & 1390 & 740 & 1860 \\
Cloud winds & $u, v$ & 2030 & 1740 & 1670 & 1510 \\
Total & & 5110 & 3550 & 3830 & 3810 \\
\hline
\end{tabular}

Previous research has shown that using deterministic lateral boundary conditions for each ensemble member leads to a lack of variance in the domain interior (e.g., Nutter et al. 2004). To address this problem, unique lateral boundary conditions for each ensemble member are specified using the fixed-covariance perturbation (FCP) technique of Torn et al. (2006) where perturbations are drawn randomly from a fixed covariance model (WRF VAR) and added to a global model forecast that is used to define the ensemble-mean lateral boundary condition. The ensemble-mean 6 -h forecast on the lateral boundaries is taken from the 12-h NCEP GFS forecast from the previous forecast cycle. By using data from the prior forecast cycle, the UW EnKF system can proceed without having to wait for the GFS forecast. Appendix A contains additional details on our WRF implementation.

Observations are assimilated from Automated Surface Observing System (ASOS) stations, ships, fixed and drifting buoys, rawinsondes, the Aircraft Communications Addressing and Reporting System (ACARS), and cloud motion vectors (Velden et al. 2005) serially using a square root version of the EnKF (Whitaker and Hamill 2002) developed at the University of Washington. Table 1 provides a summary of the number and type of observations assimilated during each analysis time, while Fig. 1 shows the horizontal distribution of rawinsondes and surface stations. Observation errors are assumed to be uncorrelated and are obtained from European Centre for Medium-Range Weather Forecasts (ECMWF) statistics.

Given a relatively small ensemble to estimate the full background error covariance matrix, the sampling error must be addressed to reduce the effects of erroneous noise. Spurious long-distance covariance relationships are addressed here by applying a distance-dependent weighting function to the covariances as defined by Eq. (4.10) of Gaspari and Cohn (1999), which reduces to zero $2000 \mathrm{~km}$ from the observation location. The ten- dency for small ensembles to underestimate covariance magnitude is addressed by adding weighted background forecast perturbations to the analysis ensemble perturbations. This "covariance relaxation" technique was proposed by Zhang et al. (2004) and is more completely described in appendix B.

Previous implementations of the EnKF have used random climatological states to initialize the ensemble (e.g., Whitaker et al. 2004; Anderson et al. 2005), but this method is potentially problematic for limited-area domains due to potential mismatches with the lateral boundary condition perturbations determined from 6-h forecasts. As a consequence, we initialize the ensemble on 1200 UTC 22 December 2004 by adding fixed covariance perturbations from the WRF VAR system to the 36-h forecast started on 0000 UTC 21 December. The perturbations are scaled by 1.8 prior to being added to this forecast so that the spread in the initial ensemble is slightly larger than the RMS error in the ensemble mean. After assimilating observations for 3 days, the ensemble-mean error and spread come into equilibrium as flow-dependent covariances develop and lose memory of the initial ensemble (not shown).

At 0000 and 1200 UTC, 24-h ensemble forecasts are obtained by integrating the analysis ensemble forward in time. For each ensemble member, lateral boundary conditions are computed using the FCP method, where the perturbation scaling factor increases from 1.6 for a 6-h forecast to 2.2 for a 24-h forecast (see appendix A for details). Ensemble-mean lateral boundary conditions are taken from the GFS forecast initialized at the previous analysis time (i.e., at 1200 UTC, the UW EnKF system uses the GFS forecast from 0600 UTC).

\section{Ensemble variance verification}

Output from the UW EnKF system is verified against mandatory-level wind, air temperature and dewpoint temperature data from the 30 rawinsonde stations located within this domain (Fig. 1a). In addition, 300 ASOS stations and fixed buoys are used to verify forecasts of surface fields (Fig. 1b). Most stations are located in the northern and eastern half of the domain, which is characterized by complex terrain. As a consequence, many of the rawinsonde observations are launched from stations well above mean sea level, thus, providing fewer verification points at $1000 \mathrm{hPa}(\approx 200$ observations over $2 \mathrm{yr}$ ) as compared with $500 \mathrm{hPa}$ ( $\approx 44000$ observations over $2 \mathrm{yr}$ ). All of the verification statistics presented here are for the 2-yr period beginning 0000 UTC 1 January 2005.

Two approaches, innovation variance statistics and rank histograms, are used to assess ensemble spread. 
Houtekamer et al. (2005) showed that for an optimally performing ensemble data assimilation system, the mean-square innovations - the diagonal elements of $E\left\{\left[\mathbf{y}-\mathcal{H}\left(\overline{\mathbf{x}}^{b}\right)\right]\left[\mathbf{y}-\mathcal{H}\left(\overline{\mathbf{x}}^{\mathrm{b}}\right)\right]^{\mathrm{T}}\right\}$, where $E\{\}$ denotes the expected value-should match the innovation variance, given by the diagonal elements of the sum of the model and observation error covariance matrices, $\left(\mathbf{H P}^{b} \mathbf{H}^{\mathrm{T}}+\mathbf{R}\right)$. The ratio of these two quantities, which we denote the error-to-variance ratio, therefore describes how well the ensemble variance is calibrated. If the ratio is less (greater) than 1, the ensemble has too much (little) variance. Since model forecasts are verified against observations, the mean-squared innovation also represents the squared error in the ensemble mean.

Rank histograms (Hamill 2001 and references therein) are constructed by sorting the ensemble estimate of the verification value from low to high, and determining the rank of the verification value within the sorted ensemble; rank populations are constructed by repeating this procedure for many locations and times. If the ensemble is unbiased and drawn from the same distribution as the true state, the population in each rank should be uniform. Excessive population in the outer (middle) ranks of the histogram indicate that truth falls outside (within) the ensemble too often, and thus the ensemble has too little (much) variance. Consistent biases in the ensemble forecasts show up as a sloped rank histogram; larger population on the left (right) side of these figures signifies that the ensemble forecast values are consistently higher (lower) than truth. Hamill (2001) showed that rank histograms can be potentially misleading if observation errors are not considered. Therefore, random errors consistent with observation error variance are added to each ensemble member's estimate of the observation.

Figures 2 and 3 show the error-to-variance ratio and rank histograms, respectively, for 6-h forecasts as a function of vertical level. Temperature forecasts generally have the appropriate spread between 300 and 700 $\mathrm{hPa}$; however, the ensemble lacks variance at other vertical levels (Fig. 2). Furthermore, below 700 hPa, rank histograms show lower (greater) population in the left (right) ranks, consistent with a model forecast cold bias (Fig. 3a). Above $500 \mathrm{hPa}$ the opposite pattern is observed; the histogram has lower (greater) population in the right (left) ranks, which indicates that the model's temperature forecasts have a warm bias.

With the exception of moisture, the variance in UW EnKF forecasts of other midtropospheric fields provides an accurate prediction of the error in the ensemble mean away from the boundary layer. Similar to temperature, the error-to-variance ratio for zonal and

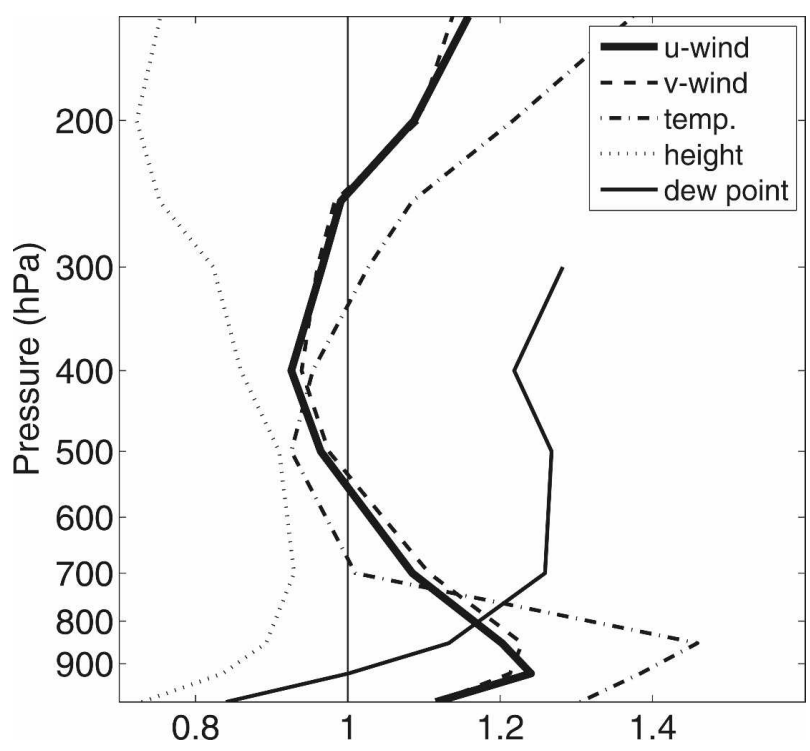

FIG. 2. Ratio of the mean-square innovations (error) to the ensemble variance $\left(\mathbf{H P}^{b} \mathbf{H}^{\mathrm{T}}+\mathbf{R}\right)$ for various 6-h UW EnKF forecasts over the 2-yr period starting 1 Jan 2005. The observations are taken from rawinsonde stations in the domain.

meridional wind is between 0.9 and 1.1 from 250 to 700 $\mathrm{hPa}$, while the ensemble spread is generally too small outside these levels (Fig. 2). Moreover, the rank histogram for the meridional wind indicates no obvious systematic bias (Fig. 3b). Variance in geopotential height forecasts exceeds the ensemble-mean error at all vertical levels (Fig. 2). Geopotential height is also lower than the observed value (Fig. 3c), which could be due in part to a bias in surface pressure (discussed below). The error-to-variance ratio for 6-h dewpoint temperature forecasts is greater than 1 throughout the column, which signals a lack of variance in this field (Fig. 2).

Although tropospheric fields below $850 \mathrm{hPa}$ are characterized by a lack of variance, UW EnKF surface field forecasts generally contain the appropriate amount of variance. Table 2 shows the error in the ensemble-mean and the sum of the variance in the model estimate and the observation error variance for 6-h surface field forecasts. For all variables except 2-m temperature, the variance is generally in good agreement with the error in the ensemble mean. Although the ensemble variance is appropriate, we note that the variance in 6-h forecasts of surface wind and temperature $\left(\mathbf{H P}^{b} \mathbf{H}^{\mathrm{T}}\right)$ are on average $25 \%$ of the observation error variance $(\mathbf{R})$, thus, the good agreement is due to the relatively larger errors in the observations.

\section{Ensemble-mean error}

In this section, the RMS error in forecasts initialized from the UW EnKF ensemble-mean analysis are veri- 

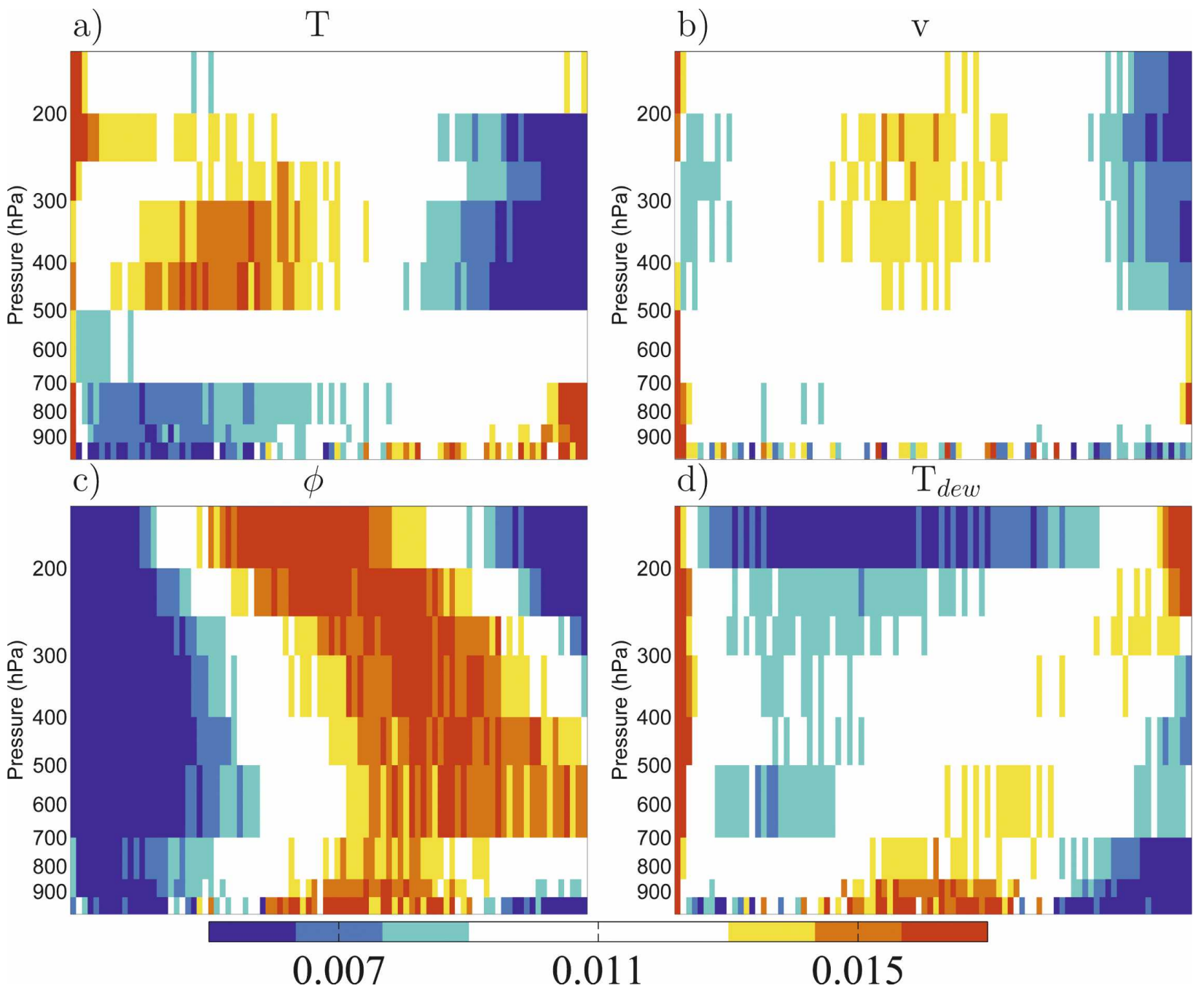

FIG. 3. Rank histograms of 6-h UW EnKF forecasts of (a) temperature, (b) meridional wind, (c) geopotential height, and (d) dewpoint temperature at various pressure levels from $1 \mathrm{Jan} 2005$ to 1 Jan 2007 verified against the rawinsonde observations. This figure is generated by independently computing rank histograms for each pressure level. Regions of blue (red) indicate that the population of that rank is less than $80 \%$ (greater than $120 \%$ ) of the expected value for a uniform distribution.

fied against rawinsonde and surface observations. For comparison, RMS errors in deterministic forecasts produced by the NCEP GFS model, the CMC GEM model, the Met Office (UKMO) unified model, and the
Navy Operational Global Atmospheric Prediction System (NOGAPS) are considered with respect to the same observations during this 2 -yr period. The initial conditions for these models are produced using differ-

TABLE 2. RMS error of UW EnKF ensemble-mean, GFS and CMC, and RMS innovation std dev (spread) for surface field forecasts verified against fixed surface stations in the domain. The values in parentheses denote the bias (forecast - observation).

\begin{tabular}{|c|c|c|c|c|c|c|}
\hline & \multicolumn{2}{|c|}{ 6-h forecast } & \multicolumn{4}{|c|}{ 24-h forecast } \\
\hline & RMS error & Spread & UW EnKF & Spread & GFS & $\mathrm{CMC}$ \\
\hline Altimeter setting $(\mathrm{hPa})$ & $2.0(-0.1)$ & 2.0 & $2.8(-0.8)$ & 2.6 & $2.0(-0.5)$ & $2.6(0.2)$ \\
\hline $10-\mathrm{m}$ zonal wind $\left(\mathrm{m} \mathrm{s}^{-1}\right)$ & $2.8(0.0)$ & 3.3 & $3.0(0.2)$ & 3.4 & $2.7(0.2)$ & $2.8(0.2)$ \\
\hline 10-m meridional wind $\left(\mathrm{m} \mathrm{s}^{-1}\right)$ & $2.8(0.2)$ & 3.3 & $3.0(0.1)$ & 3.4 & $2.6(0.0)$ & $3.1(-0.1)$ \\
\hline $2-\mathrm{m} T(\mathrm{~K})$ & $3.7(-0.1)$ & 2.8 & $3.9(-0.1)$ & 2.9 & $3.5(-0.2)$ & $3.9(-0.5)$ \\
\hline 2-m dewpoint temperature $(\mathrm{K})$ & $4.0(0.9)$ & 4.1 & $4.1(0.8)$ & 4.5 & $4.1(0.7)$ & $4.5(1.7)$ \\
\hline
\end{tabular}


(a)

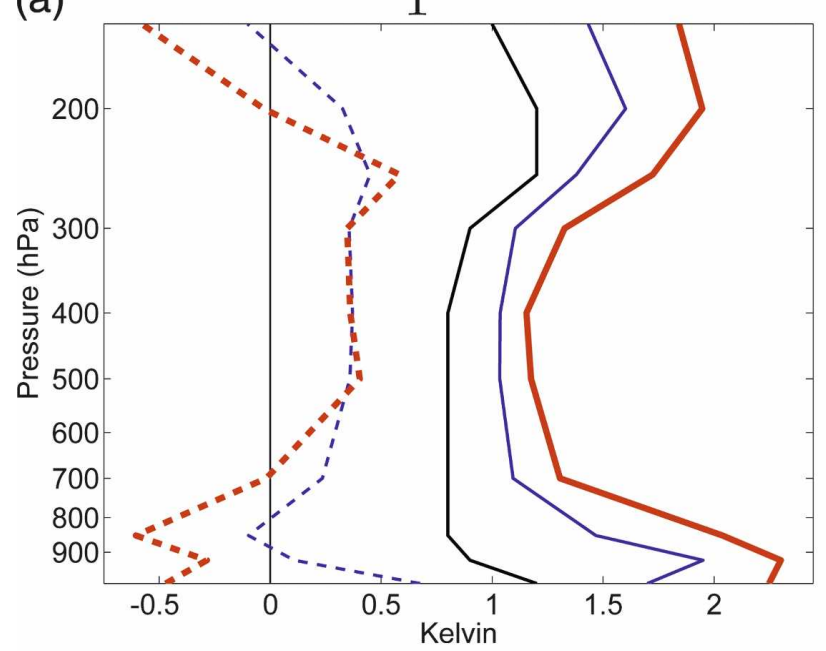

(c)

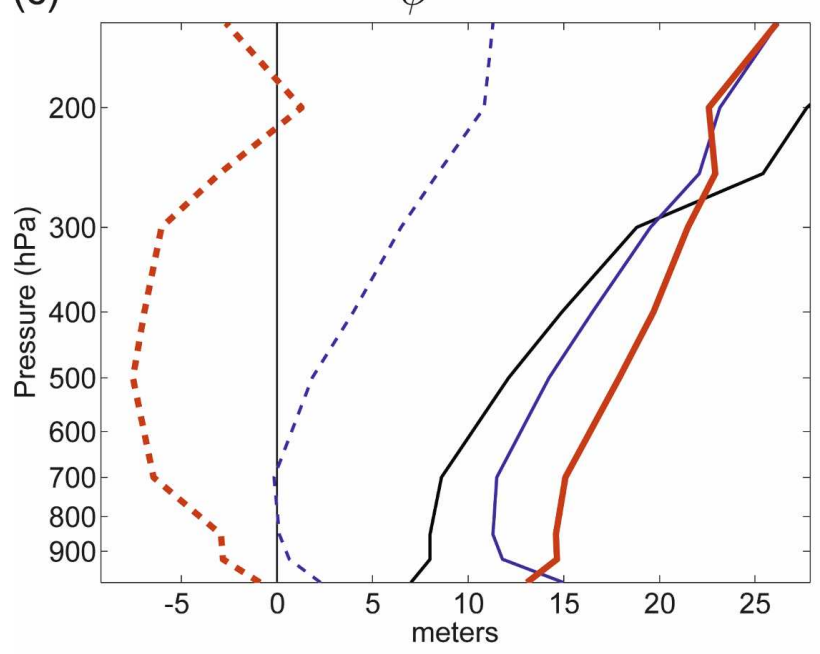

(b)

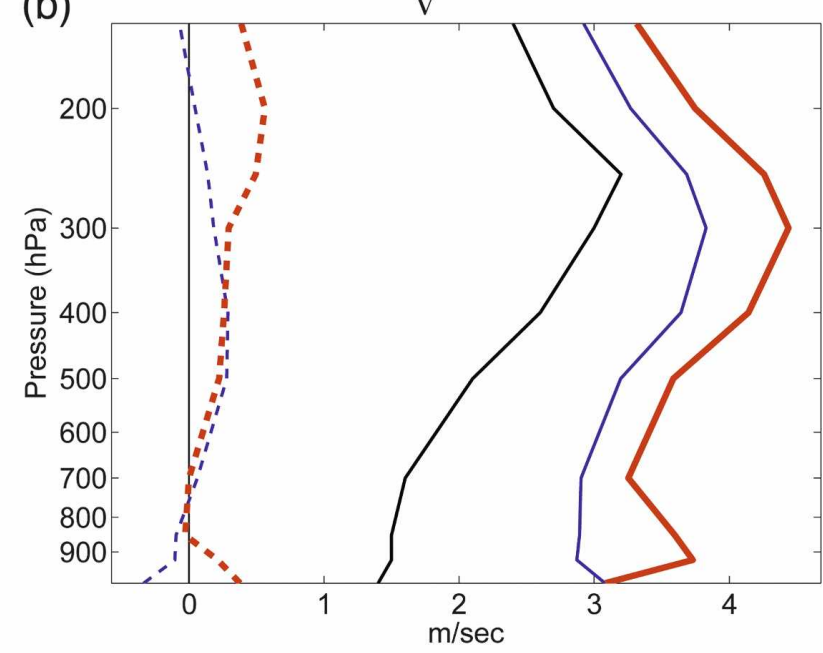

(d)

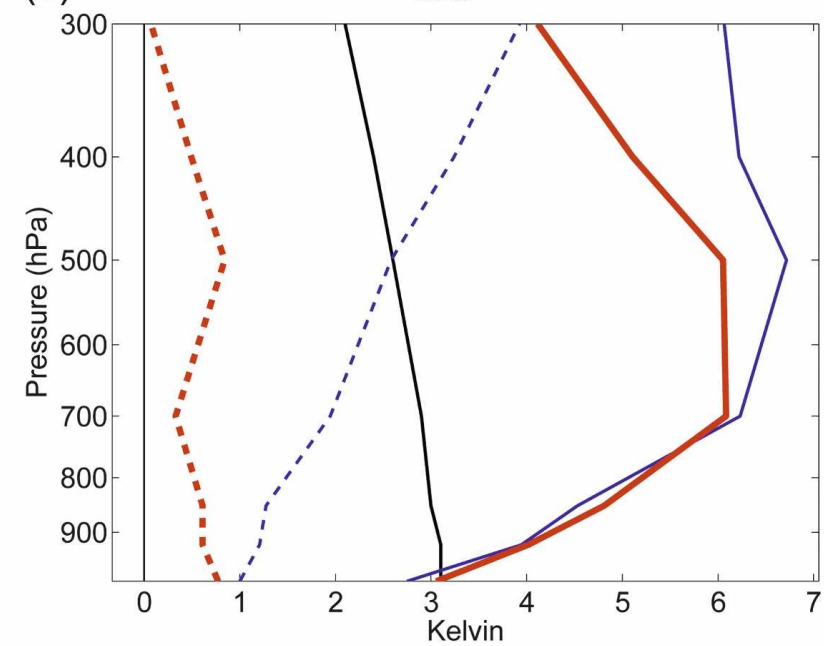

WRF EnKF

GFS

FIG. 4. RMS error (solid) and bias (forecast - observation, dashed) in 6-h forecasts of (a) temperature, (b) meridional wind, (c) geopotential height, and (d) dewpoint temperature over the UW EnKF domain from 1 Jan 2005 to 1 Jan 2007. All forecasts are verified against the same set of rawinsonde observations. The black line denotes the ECMWF rawinsonde observation error std dev assumed during data assimilation.

ent assimilation techniques and observations; however, these models have roughly the same horizontal resolution as the UW EnKF system. ${ }^{1}$

Figures $4 \mathrm{a}$ and 5a shows that the RMS error in UW EnKF temperature forecasts are similar to some of the

\footnotetext{
${ }^{1}$ The available output files are degraded from the native model resolution $\left(\approx 1^{\circ}\right.$ lat-lon $)$. Moreover, with the exception of GFS, data are only available for forecasts initialized at 0000 and 1200 UTC. Nevertheless, this comparison is meant to demonstrate the skill of UW EnKF forecasts relative to other forecasting systems that employ larger observation sets, including satellite radiances.
}

operational forecasting systems shown here. Specifically, the RMS error in UW EnKF 6-h temperature forecasts is approximately $0.15 \mathrm{~K}$ larger than for the GFS. For 24-h forecasts, the UW EnKF is $0.3 \mathrm{~K}$ larger than GFS; however, below $300 \mathrm{hPa}$ the UW EnKF error values are within $0.1 \mathrm{~K}$ of the UKMO and NOGAPS forecasts (Fig. 5a). This result is notable because the UW EnKF system assimilates only a small fraction of the observations used by operational centers (the UW EnKF does not assimilate satellite radiances). Potential explanations for this result include assimilating observations with flow-dependent error statistics, 
(a)

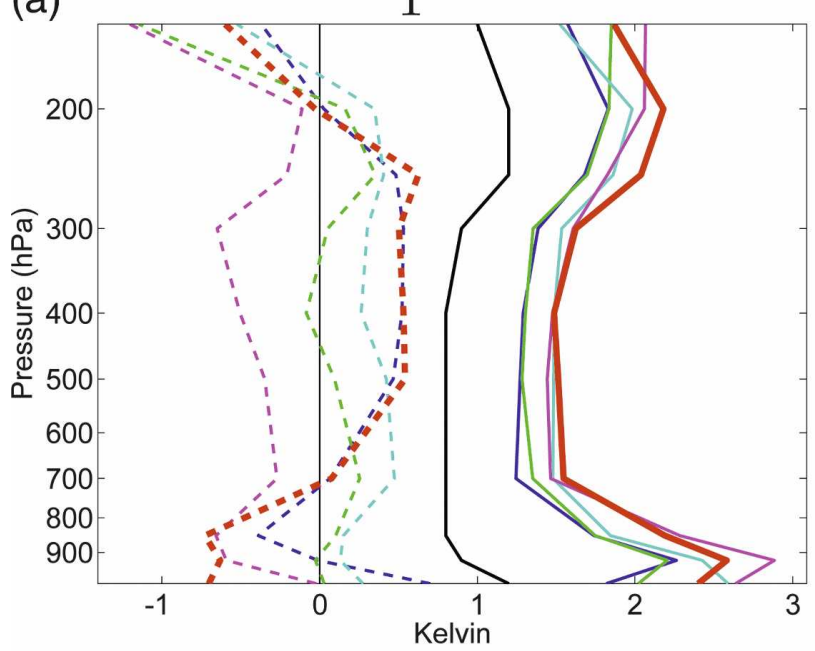

(c)

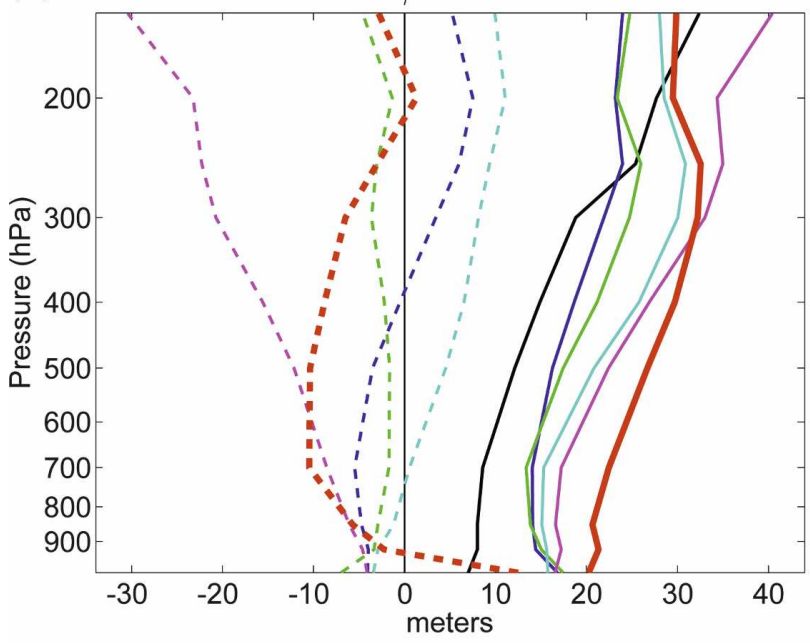

(b)

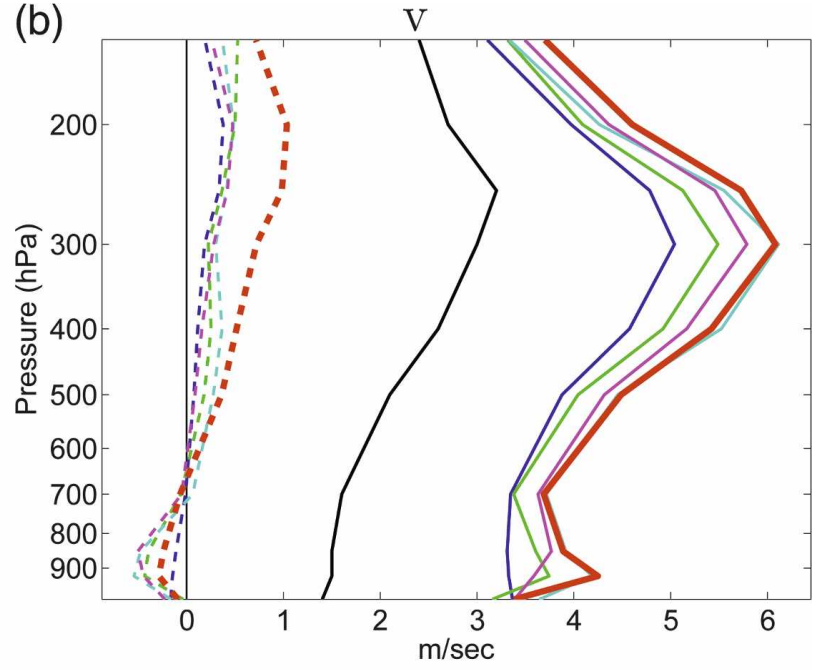

(d)

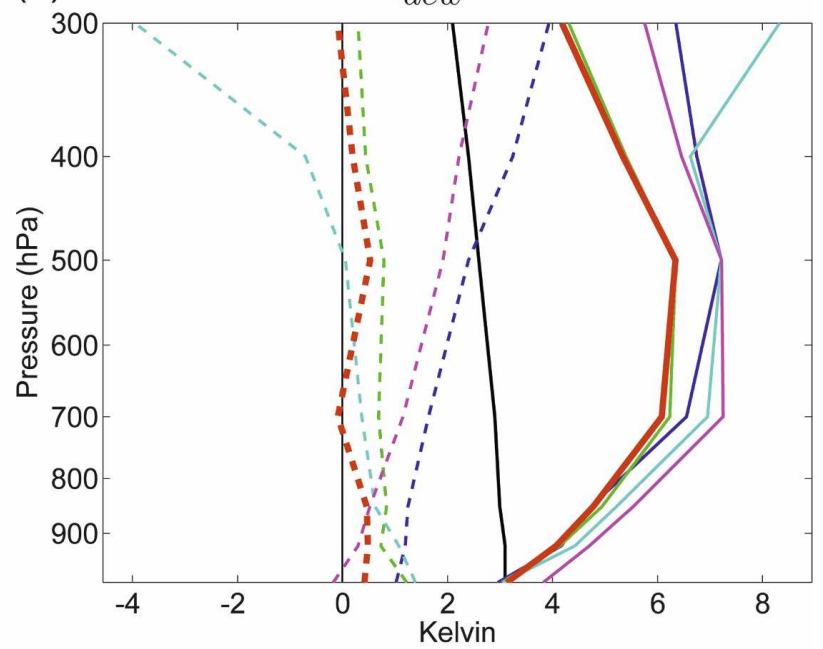

WRF EnKF

CMC

UKMO

NOGAPS

FIG. 5. As in Fig. 4, but for 24-h forecasts.

model formulation, and lateral boundary conditions. The role of each of these possible factors is evaluated in section 5, where UW EnKF forecasts are compared to WRF forecasts with different initial conditions.

We note that the favorable comparison between UW EnKF temperature forecasts and other operational systems is not uniform for all rawinsonde stations in the domain, especially in the lower troposphere. At 850 $\mathrm{hPa}$, the RMS error (bias) in 6-h temperature forecasts for rawinsondes launched near sea level is less than 0.5 (0.1) $\mathrm{K}$; however, for the two stations above 1000-m elevation, Fort Nelson (CYYE) and Edmonton (CWSE), RMS errors exceed $2.0 \mathrm{~K}$ with a bias of -1.5 $\mathrm{K}$ (colder than observations). Moreover, the $850-\mathrm{hPa}$ temperature observation innovations for these two sta- tions are correlated at 0.75 , which suggests a problem in the model's high elevation boundary layer. In contrast, the RMS error and bias in 6-h temperature forecasts in the upper troposphere are more uniform among all stations and the innovations are uncorrelated (not shown).

RMS error in UW EnKF forecasts of other tropospheric quantities are comparable to the operational centers presented here; for brevity, only 24 -h forecasts are described (Fig. 5). Errors in UW EnKF meridional wind forecasts (Fig. 5b), which increase from $4 \mathrm{~m} \mathrm{~s}^{-1}$ at $850 \mathrm{hPa}$ to $6 \mathrm{~m} \mathrm{~s}^{-1}$ at $300 \mathrm{hPa}$, are roughly $1 \mathrm{~m} \mathrm{~s}^{-1}$ larger than GFS forecasts, but similar to those obtained for UKMO forecasts. For geopotential height, the error in UW EnKF forecasts is larger than all operational 
models throughout the troposphere (Fig. 5c). A $10-\mathrm{m}$ geopotential height bias at $500 \mathrm{hPa}$ is consistent among all rawinsonde stations and, furthermore, the innovations are correlated above 0.85 , which suggests that the version and configuration of WRF used here has a systematic bias in the mass field.

RMS errors in 24-h UW EnKF dewpoint temperature forecasts increase from $3 \mathrm{~K}$ at $1000 \mathrm{hPa}$ to a maximum of $6 \mathrm{~K}$ at $500 \mathrm{hPa}$ (Fig. 5d), but unlike the other described fields, these values are smaller than most other models, especially in the midtroposphere.

Whitaker et al. (2008) showed that their GFS EnKF system had lower moisture forecast errors than the GFS 3DVAR system, although it is notable that for the results reported here, operational centers assimilate remotely sensed humidity observations, which are absent in the Whitaker et al. (2008) simulations. Potential reasons for lower errors in UW EnKF moisture fields will be explored in the next section.

The EnKF system described in Houtekamer et al. (2005) was characterized by decreasing ensemble spread at short forecast lead times, which suggests that their analysis perturbations project preferentially onto the decaying modes of the model (e.g., Houtekamer et al. 2005, their Fig. 8). To determine the rate of error growth in UW EnKF system, the RMS error in the ensemble-mean forecast and the RMS spread are computed for various fields, vertical levels, and forecast lead times. Figure 6 shows that the error and spread in temperature, meridional wind, and geopotential height forecasts increase at all forecast hours and are characterized by a doubling time of approximately 2 days, which is roughly consistent with the value obtained by Lorenz (1982). In contrast to the other fields, the dewpoint temperature forecasts have smaller growth in ensemble-mean error and ensemble spread (Fig. 6d). Forecasts of $500-\mathrm{hPa}$ dewpoint temperature have a doubling time of 8 days, and are in line with the values obtained for the other operational systems described here. One possible reason for the difference in error growth between the UW EnKF system and the Houtekamer et al. (2005) implementation is the covariance inflation method. Recall that the UW EnKF system boosts the variance of the analysis ensemble via covariance relaxation, where more weight is given to the background forecast's deviation from the mean. As a consequence, the analysis perturbations probably project preferentially onto the growing modes from the previous $6 \mathrm{~h}$.

In contrast to the results for upper-level fields, the bias and error in forecasts of surface fields, with the exception of altimeter setting, show little difference among all forecast hours (Table 2). The RMS error in
UW EnKF altimeter setting forecasts increases from 2.0 to $2.7 \mathrm{hPa}$ for the 6-24-h lead times; these values are larger than GFS forecasts, but are smaller than those for the NOGAPS and UKMO models (not shown). Although UW EnKF 6-h altimeter setting forecasts show small bias, the 24 -h forecast is on average $0.8 \mathrm{hPa}$ lower than surface observations, and is consistent with the low bias in geopotential heights (cf. Fig. 5c). Unlike altimeter setting, the error and spread in $10-\mathrm{m}$ wind, 2-m temperature, and 2-m dewpoint temperature forecasts are similar for all models and lead times. Errors in these parameterized surface fields can result from deficiencies in the dynamical fields that serve as inputs, and errors in the boundary layer model formulation. Since the error and spread in the input dynamical fields (e.g., lower-tropospheric temperature and wind) increase with time (Fig. 6), the relative constancy of surface errors suggests that deficiencies in the boundary layer model are the dominant error source.

\section{Comparison with control forecasts}

Here we explore two factors that may affect forecast skill on limited-area domains: lateral boundary conditions and model formulation. Errico and Baumhefner (1987) demonstrated that predictability on limited-area domains is enhanced by the information contained in the lateral boundary conditions. The impact of lateral boundary conditions is assessed here by cycling an additional ensemble member over the 2 -yr period with the same lateral boundary conditions as the ensemblemean forecast, but without assimilating observations. Differences between this "no assimilation" forecast and the ensemble-mean 6-h forecast are thus solely attributable to observation assimilation.

Figure 7 shows that observation assimilation leads to systematically lower errors than the case where data assimilation is not performed. RMS errors in the forecast initialized from the ensemble-mean analysis are up to $50 \%$ smaller than the no-assimilation forecast, suggesting that the skill of the UW EnKF forecasts is not due to the GFS lateral boundary conditions. The largest (smallest) differences between these two forecasts are in the middle and upper (lower) troposphere where the error in UW EnKF forecasts is comparable (larger than) the other operational centers. Furthermore, the bias in both UW EnKF and no-assimilation forecasts are qualitatively similar, except for geopotential height, which is $50 \%$ smaller when observations are assimilated. This result suggests that observation assimilation reduces the bias in WRF mass field forecasts. In contrast, parameterized surface fields show limited error reduction due to assimilation (Table 3 ). Whereas the error in 6-h UW EnKF altimeter setting forecast are 
(a)

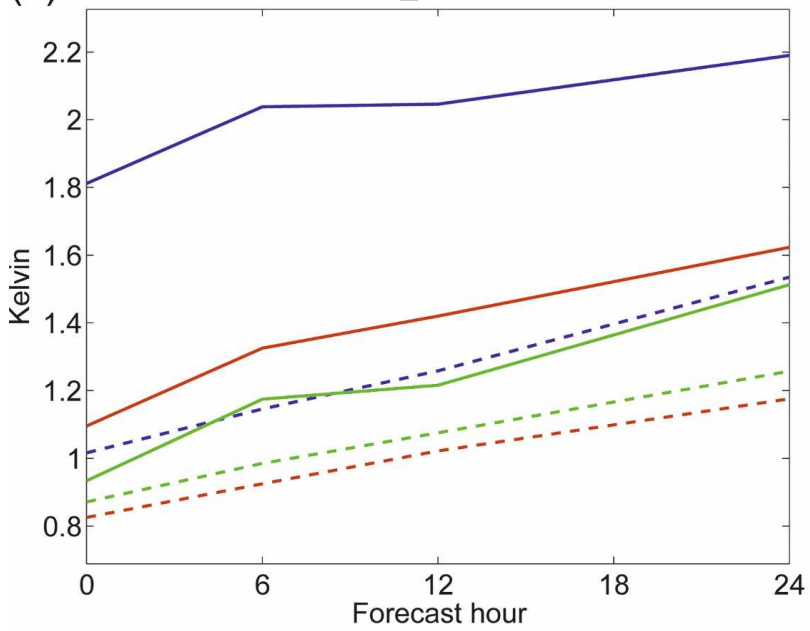

(c)

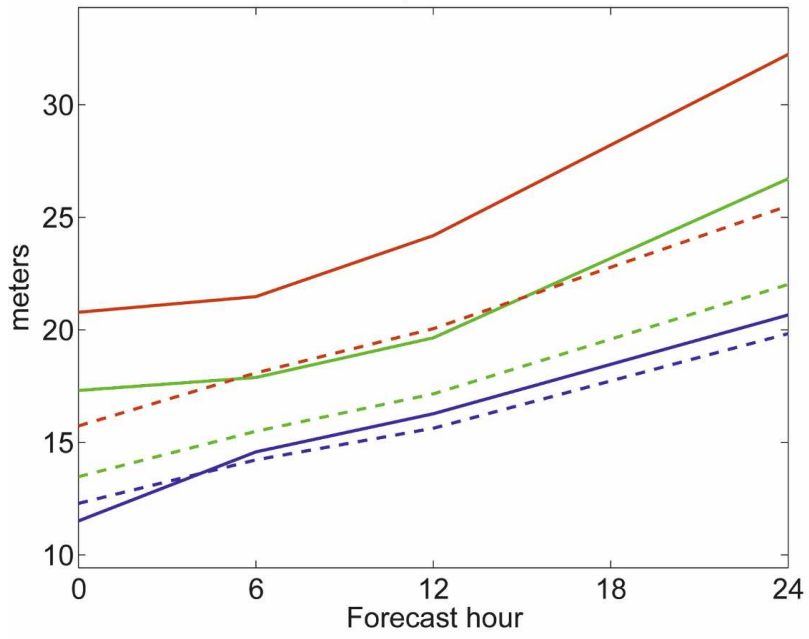

(b)

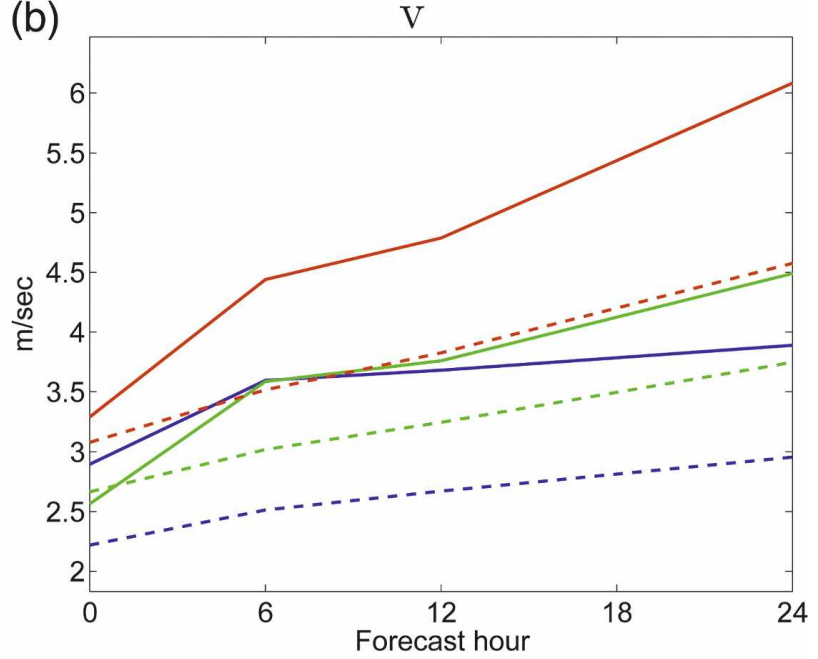

(d)

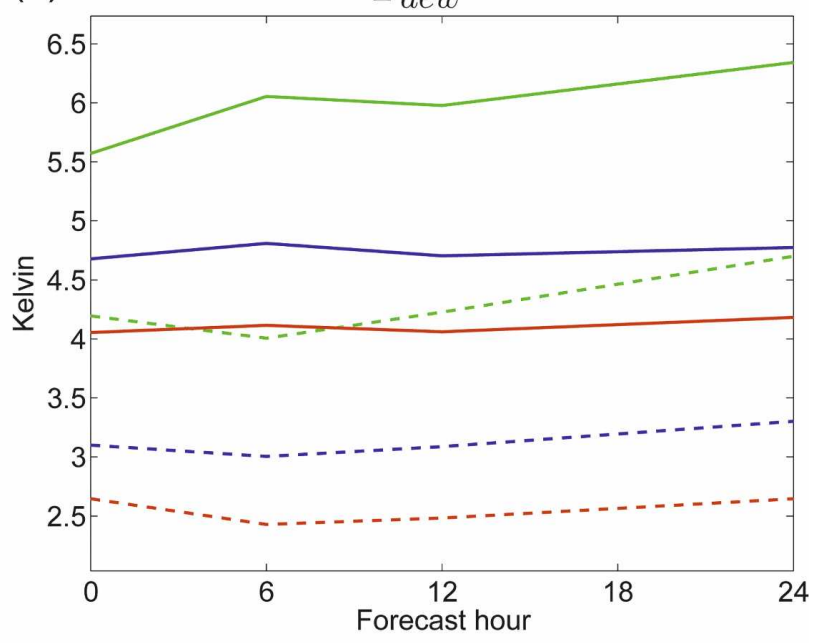

$$
-550 \mathrm{hPa}-500 \mathrm{hPa}-30 \mathrm{hPa}
$$

FIG. 6. RMS error in the ensemble mean (solid line) and the RMS ensemble spread (dashed line) in UW EnKF forecasts of (a) temperature, (b) meridional wind, (c) geopotential height, and (d) dewpoint temperature as a function of forecast hour from 1 Jan 2005 to 1 Jan 2007. Forecasts are verified against rawinsonde observations.

$43 \%$ smaller than the no-assimilation forecast, more modest decreases of $18 \%, 15 \%$, and $15 \%$ are obtained for 10-m winds, 2-m temperature, and 2-m dewpoint temperature, respectively. The difference between the forecast from the ensemble-mean and no-assimilation surface field forecasts further supports the hypothesis that errors in these forecasts are primarily due to model bias.

Another possible reason for the relatively skillful UW EnKF forecasts is that the WRF model formulation is better than the others described here. This possibility is assessed by comparing WRF forecasts initialized with UW EnKF ensemble-mean analyses to WRF forecasts initialized with GFS analyses (denoted WRF-
GFS) at 0000 and 1200 UTC. All model settings and lateral boundary conditions are the same, so that differences between the UW EnKF ensemble-mean and WRF-GFS forecasts are due solely to initial conditions. Furthermore, WRF-GFS and GFS forecasts use approximately the same initial conditions, thus, differences between the two result from the model formulation.

Although the initial conditions are generated by two different data assimilation techniques and different observation sets, Fig. 8 indicates that the RMS error in 24-h UW EnKF forecasts are approximately $10 \%$ larger than the WRF-GFS forecasts, except for uppertropospheric winds and geopotential height. Further- 
(a)

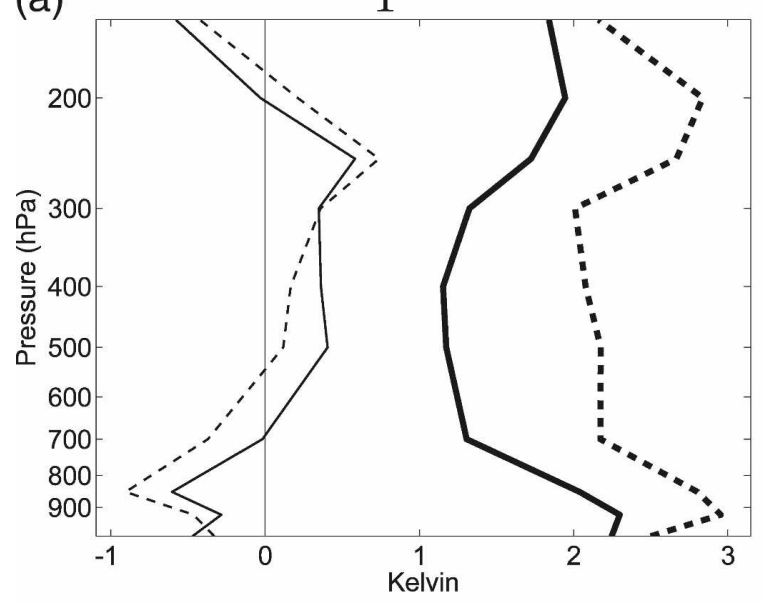

(c)

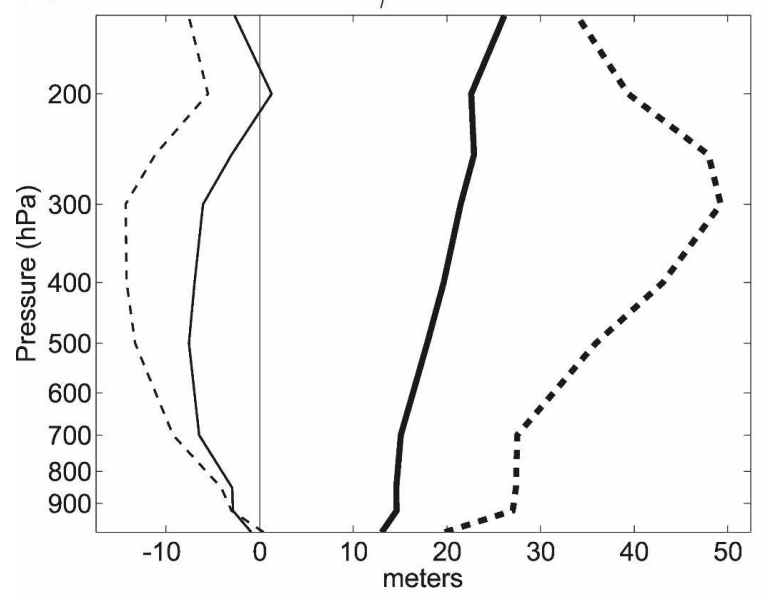

(b)

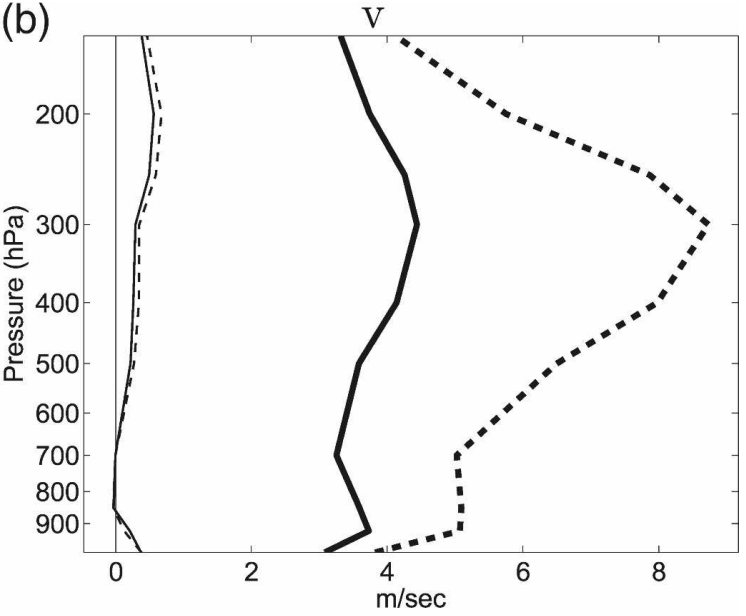

(d)

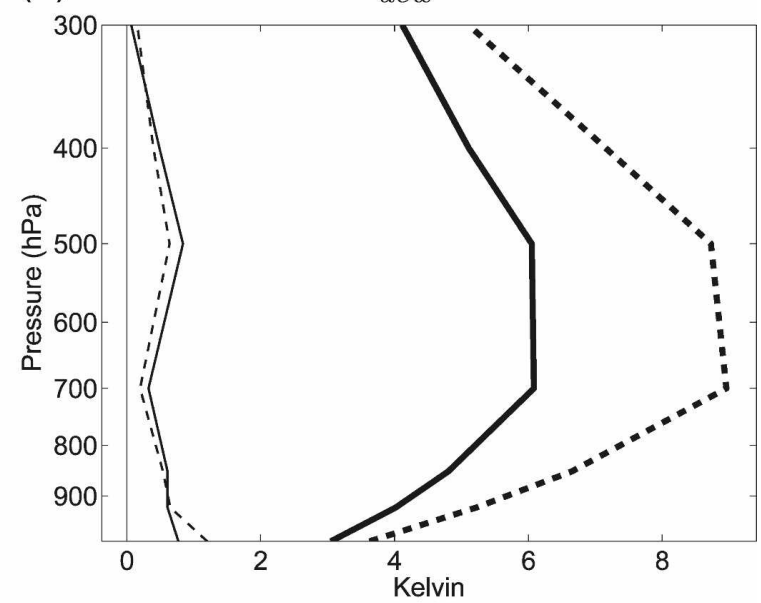

Control --- No assimilaton member

FIG. 7. RMS error (thick lines) and bias (forecast - observation, thin lines) in the no-assimilation and the 6-h forecast initialized from the ensemble-mean analysis of (a) temperature, (b) zonal wind, (c) geopotential height, and (d) dewpoint temperature verified against rawinsonde observations as a function of pressure from 1 Jan 2005 to 1 Jan 2007.

more, comparing Figs. 5 and 8 shows that the error in 24-h WRF-GFS and GFS forecasts are within $5 \%$ of each other, except for geopotential height, thus, the WRF model initialized with the GFS analysis does not have more skill than a GFS forecast. Moreover, WRF-
GFS results indicate that the WRF model biases exist when GFS initial conditions are used, further suggesting that the bias results from the model, rather than assimilating observations.

One potential reason for why the RMS error in UW

TABLE 3. RMS error (bias) in UW EnKF ensemble-mean, no-assimilation, and WRF-GFS surface field forecasts verified against fixed surface observations in the domain.

\begin{tabular}{|c|c|c|c|c|}
\hline & \multicolumn{2}{|c|}{ 6-h forecast } & \multicolumn{2}{|c|}{ 24-h forecast } \\
\hline & UW EnKF Mean & No assimilation & UW EnKF mean & WRF-GFS \\
\hline Altimeter setting $(\mathrm{hPa})$ & $2.0(-0.1)$ & $3.5(0.0)$ & $2.8(-0.8)$ & $2.6(-0.7)$ \\
\hline $10-\mathrm{m}_{\text {zonal }}$ wind $\left(\mathrm{m} \mathrm{s}^{-1}\right)$ & $2.8(0.0)$ & $3.4(0.1)$ & $3.0(0.2)$ & $3.1(0.2)$ \\
\hline 10-m meridional wind $\left(\mathrm{m} \mathrm{s}^{-1}\right)$ & $2.8(0.2)$ & $3.4(0.1)$ & $3.0(0.1)$ & $3.1(0.2)$ \\
\hline $2-\mathrm{m} T(\mathrm{~K})$ & $3.7(-0.1)$ & $4.1(0.0)$ & $3.9(-0.1)$ & $3.8(-0.4)$ \\
\hline 2-m dewpoint temperature $(\mathrm{K})$ & $4.0(0.9)$ & $4.6(0.7)$ & $4.1(0.8)$ & $4.2(1.3)$ \\
\hline
\end{tabular}


(a)

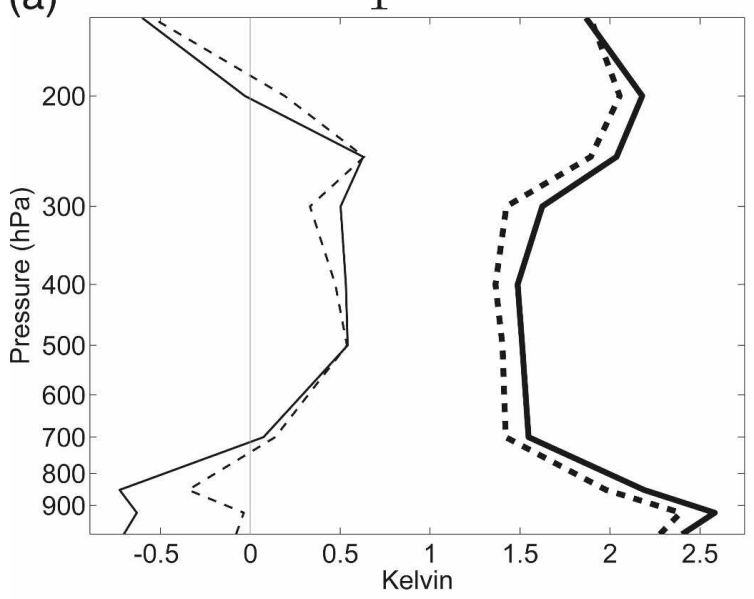

(c)

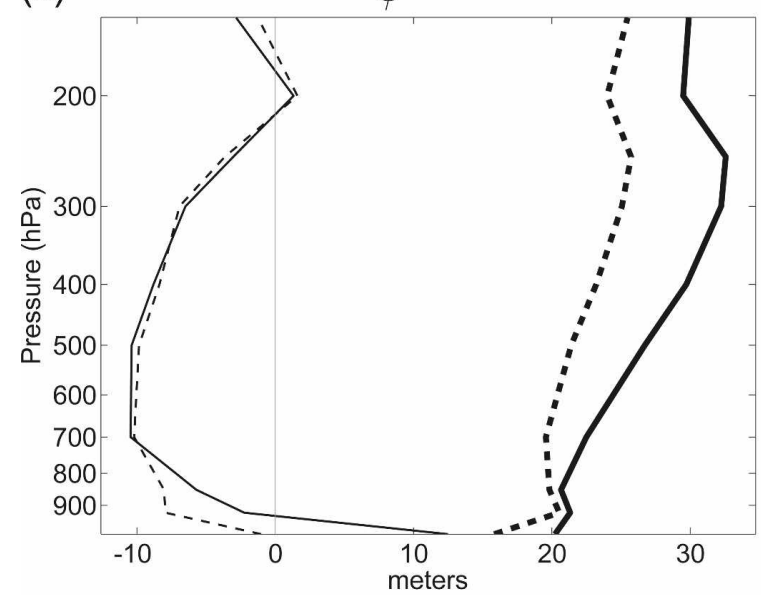

(b)

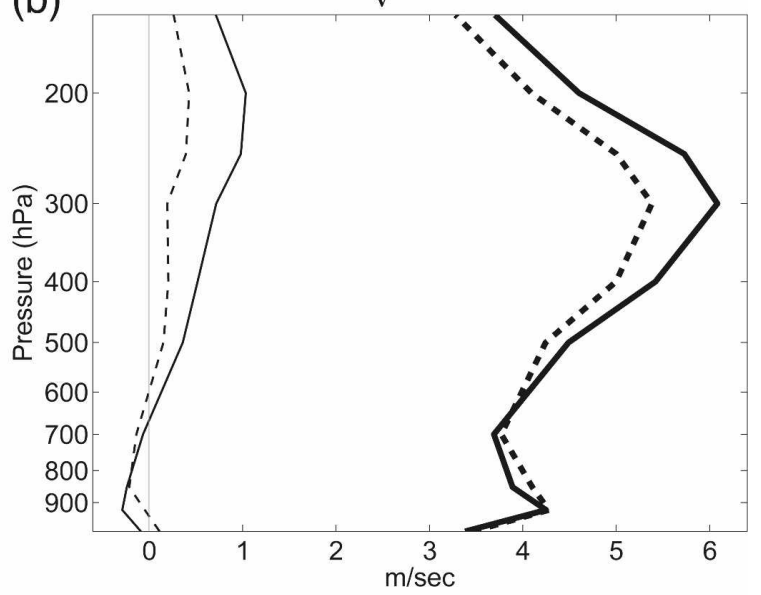

(d)

$\mathrm{T}_{\text {dew }}$

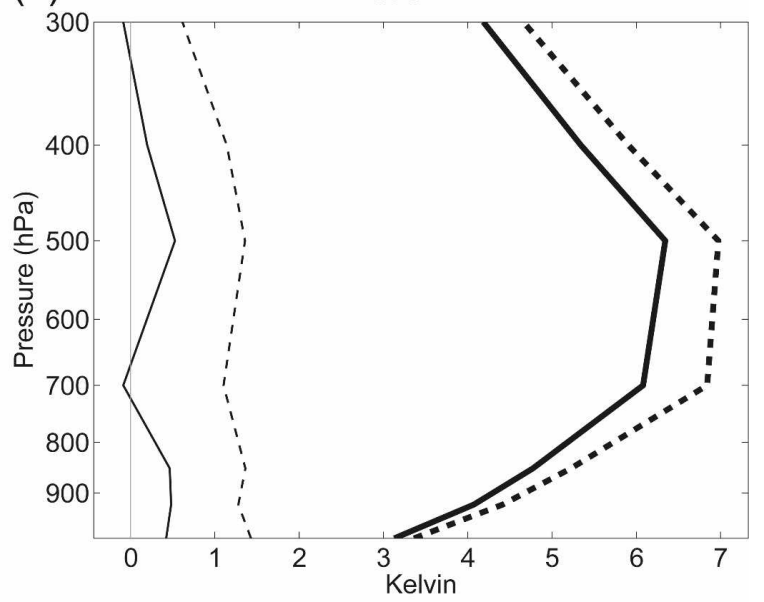

Control - - - WRF-GFS

FIG. 8. As in Fig. 7, but for the 24-h UW EnKF forecast from the ensemble-mean and WRF-GFS forecasts.

EnKF dewpoint temperature forecasts is lower than GFS forecasts could relate to each model's microphysics parameterization; however, Fig. 8d shows that UW EnKF dewpoint forecasts have lower errors than WRFGFS forecasts. This result implies that the UW EnKF system has a better analysis of the moisture field. Since the EnKF uses flow-dependent error statistics to spread observation information, wind and temperature observations can correct the moisture field. In contrast, the quasi-fixed error statistics used in the GFS analysis system during this period allow only moisture observations (e.g., rawinsondes or satellites) to adjust the water vapor field (D. Parrish, NCEP, 2008, personal communication).

To better understand what observation types affect the moisture field, time-averaged correlations between the water vapor mixing ratio and the temperature and winds in the column are computed using the $N(90)$ - member 6-h forecast ensemble. Figure 9 shows the time-averaged ensemble correlation between the water vapor mixing ratio at vertical level $k_{1}$ and another state variable at level $k_{2}$, which is computed via

$$
C\left(q_{i, k_{1}}, x_{i, k_{2}}\right)=\frac{1}{N_{t}} \sum_{t=1}^{N_{t}} \frac{1}{N-1} \frac{\mathbf{q}_{i, k_{1}, t}^{\prime} \mathbf{x}_{i, k_{2}, t}^{\prime \mathrm{T}}}{\sigma_{q_{i, k_{1}, t}} \sigma_{x_{i, k_{2}, t}}}
$$

Here $\mathbf{x}_{i, k_{2}, t}^{\prime}$ and $\mathbf{q}_{i, k_{1}, t}^{\prime}$ are the $1 \times N$ ensemble estimates of a state variable and the water vapor mixing ratio, respectively, at horizontal location $i$, and time $t$, with the ensemble mean removed, $\sigma$ denotes the ensemble standard deviation, and $N_{t}$ is the number of times used to compute the average (i.e., 1460). Regions of nonzero correlation indicate the vertical levels where observations, on average, affect the moisture field.

Although there is little correlation between the water 
(a)

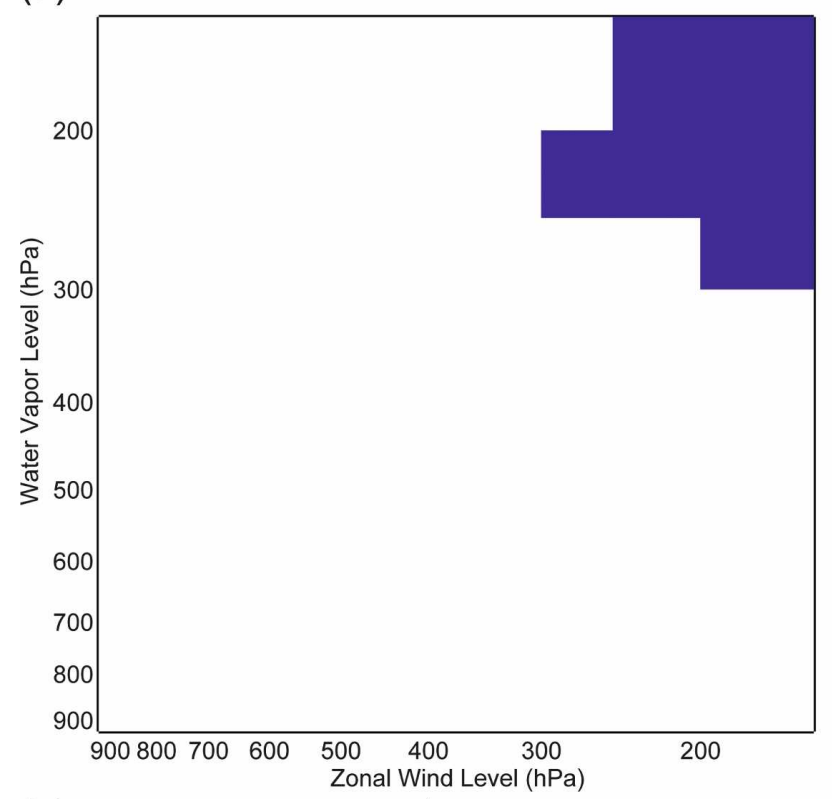

(c)

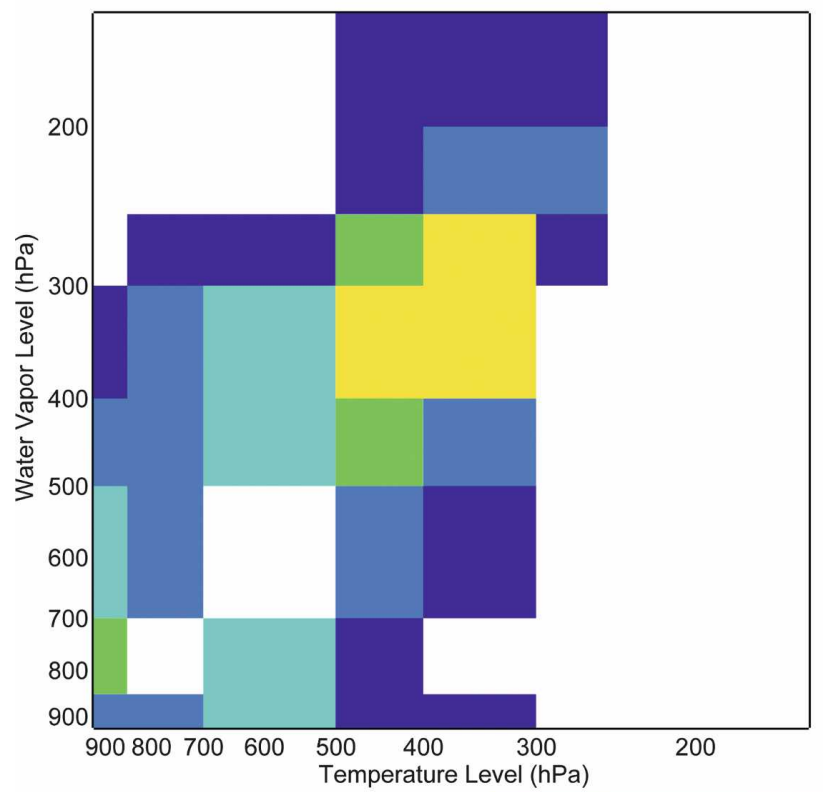

(b)

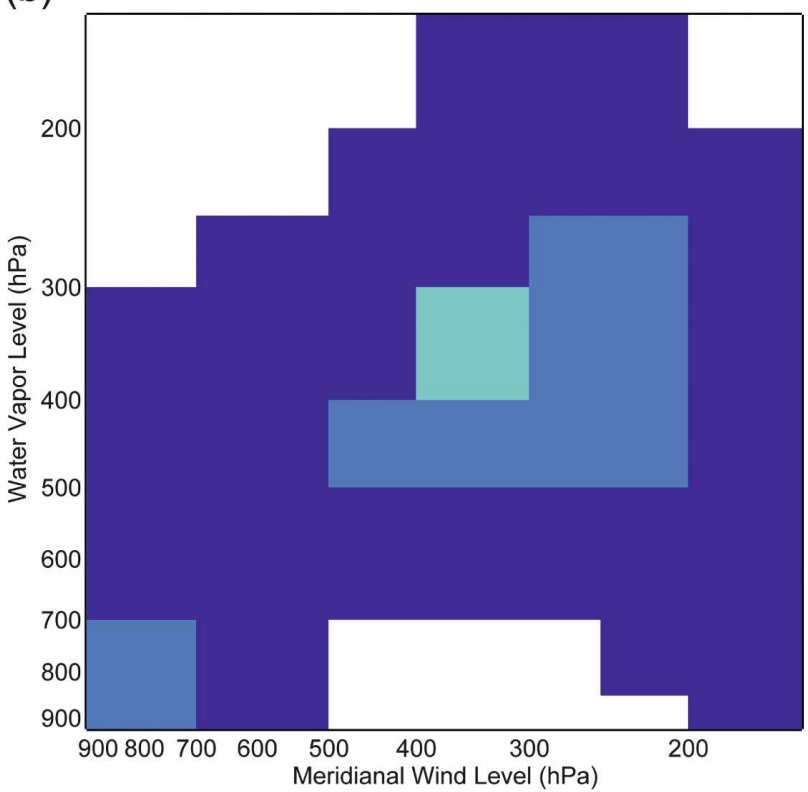

$\mathrm{T}_{\text {dew }}$

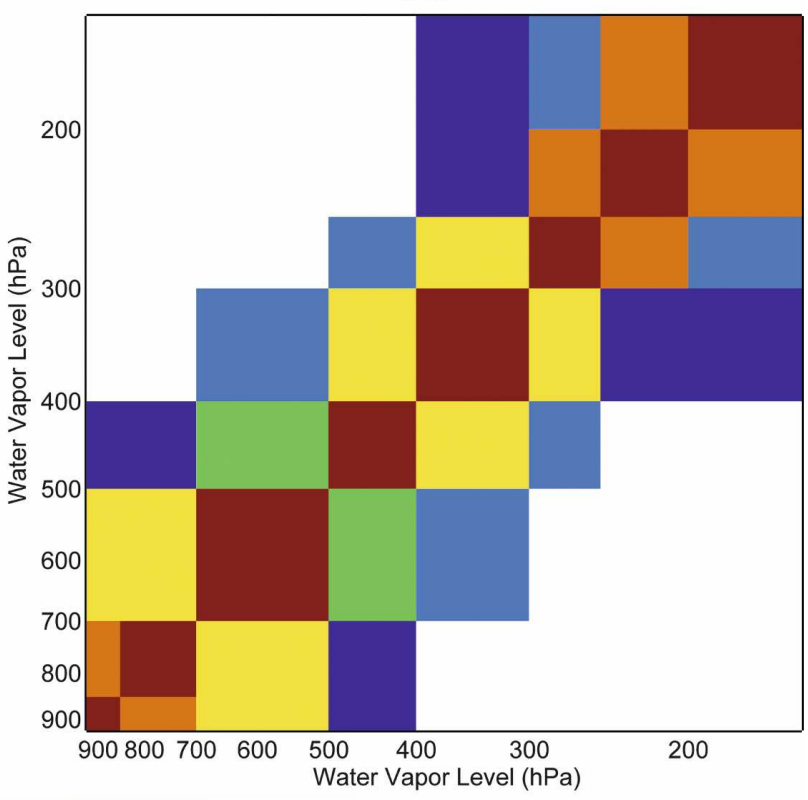

\section{$\begin{array}{llll}0.2 & 0.4 & 0.6 & 0.8\end{array}$}

FIG. 9. Mean correlation between the 6-h forecast of water vapor mixing ratio and (a) zonal wind, (b) meridional wind, (c), temperature, and (d) water vapor mixing ratio at each mandatory pressure level $(925-150 \mathrm{hPa})$. This figure is constructed by computing the correlation from the 90-member 6-h forecast ensemble every $6 \mathrm{~h}$ and averaging over time from $1 \mathrm{Jan} 2005$ to $1 \mathrm{Jan} 2007$.

vapor mixing ratio and the zonal component of the wind (Fig. 9a), time-average correlations in excess of 0.12 exist between the upper-troposphere meridional wind and water vapor fields (Fig. 9b); presumably this result is due to a time-mean north-south gradient of water vapor. We note that the RMS error in UW EnKF 24-h dewpoint temperature forecasts is $15 \%$ lower than GFS forecasts at these pressure levels (Fig. 5d), and up to $25 \%$ smaller for stations along the North American coast. The primary source of observational data up- 
stream of these locations is cloud motion vectors, which are most numerous in the upper troposphere. These results seem to indicate that even though cloud motion vectors typically have large errors (Bormann et al. 2003), they can yield important corrections to the moisture field.

Figure $9 \mathrm{c}$ shows that the average correlation between midtropospheric temperature field and midtropospheric water vapor mixing ratio is approximately 0.15 with nonzero correlations extending above and below that level. As a consequence, upper-tropospheric temperature observations, such as from transcontinental aircraft, can have an impact on the water vapor mixing ratio throughout the column. For comparison the correlation between the water vapor mixing ratio at various pressure levels is shown in Fig. 9d, which by definition is unity at the same pressure level. In general, the correlation between water vapor mixing ratio at two different levels is greater than 0.16 for pressure levels within $200 \mathrm{hPa}$ of each other.

Comparison of the error in UW EnKF and WRFGFS surface field forecasts indicates that the skill in these fields does not seem to depend on initial conditions (Table 3). Although WRF-GFS forecasts of altimeter setting have slightly lower error than the UW EnKF, other surface fields have similar errors; the UW EnKF 2-m temperature and dewpoint forecasts have slightly smaller biases.

\section{Discussion and conclusions}

This paper describes the performance of a pseudooperational, limited-area ensemble Kalman filter system during a 2-yr period starting 1 January 2005. The purpose of this system is to determine the benefit of assimilating observations with flow-dependent error statistics in a region of sparse in situ data and complex topography. Whereas operational data assimilation systems are dominated in number by satellite radiance data, the UW EnKF system utilizes only observations from surface stations, rawinsondes, ACARS, and cloud motion vectors. In addition to assimilating observations every $6 \mathrm{~h}$, the UW EnKF system produces 90 independent 24-h forecasts at 0000 and 1200 UTC. Ensemble forecasts from this system and deterministic forecasts from operational global models are verified against rawinsonde and surface observations on this domain.

Although the UW EnKF system assimilates only a small fraction of the observations available to operational centers, the RMS error in UW EnKF wind and temperature forecasts is similar to those found for the NOGAPS and UKMO models and larger than GFS and $\mathrm{CMC}$ forecasts in this region. In contrast, the bias in UW EnKF geopotential height forecasts leads to errors that are slightly larger than these other operational systems. A no-assimilation WRF forecast, which is cycled over this 2-yr period without assimilation and thus defines the contribution from the lateral boundary conditions, has RMS errors that are up to $50 \%$ larger than 6-h UW EnKF forecasts. Moreover, WRF forecasts initialized from the GFS analysis yield errors that are comparable to GFS model forecasts. As a consequence, the performance of the UW EnKF system must be due to assimilating observations with flowdependent error statistics and not boundary conditions or differences in model formulation.

A notable result is that the error in 24-h UW EnKF dewpoint temperature forecasts are equal to or smaller than all operational centers shown here, especially for stations along the North American coast. Timeaveraged correlations computed from 6-h UW EnKF forecasts show that upper-tropospheric wind and midtropospheric temperature are correlated with the water vapor field, suggesting that cloud motion wind and ACARS temperature observations have a significant impact on the moisture analysis. Previous studies (e.g., Ralph et al. 2004; Knippertz and Martin 2007) have shown that global model moisture forecasts in cloudy regions are often characterized by large shortterm forecast errors. The results shown here suggest that this problem may be reduced by assimilating other available observations, such as cloud wind data, with flow-dependent error statistics.

Unlike the EnKF system described by Houtekamer et al. (2005), the spread in UW EnKF forecasts grows in tandem with the ensemble-mean error during all forecast hours, suggesting that analysis errors project preferentially onto growing disturbances. Consistent error growth at all forecast hours likely results from our choice of covariance inflation, which at least partially retains the growing structures from the previous 6-h forecast.

The spread in ensemble forecasts of wind, temperature and moisture shows skill in predicting the forecast error; however, the mass field is characterized by relatively large bias. For short lead times, observation assimilation acts to reduce the bias, but at longer lead times, the WRF forecast is characterized by surface pressure and geopotential height values that are lower than observations.

Similar to other mesoscale ensemble systems based on different initial conditions (e.g., Eckel and Mass 2005), forecasts of parameterized surface fields, such as 10-m winds and 2-m air temperature and dewpoint temperature, are characterized by minimal growth in error and ensemble spread with time, suggesting that errors 
in the boundary layer model are a limiting factor. Surface and boundary layer parameterization schemes have two different types of input: dynamical fields that are different for each ensemble member (i.e., low-level temperature and wind), and fixed fields that are the same for each member (i.e., solar constant and land surface type). The relative lack of growth in ensemble spread suggests that the static input fields limit error growth. Although the UW EnKF system did not assimilate surface wind, temperature, or moisture data, the lack of variance in these fields probably would have caused the data assimilation scheme to underweight the new information from observations. As a consequence, flow-dependent error statistics may not produce better near-surface analyses unless the variance of these fields is larger. Sutton et al. (2006) attempted to overcome the lack of variance in surface variables in a convective situation by adding uncertainty to soil moisture fields. Their results indicate that adding variance to the soil moisture showed limited improvement over using the same soil moisture fields for all ensemble members. We note that representativeness errors in surface observations can lead to large innovations, which when combined with flow-dependent error statistics, can lead to erroneously large increments in other tropospheric fields.

In addition to demonstrating the applicability of an EnKF to limited-area domains with real data, the output from this system can be used for predictability studies over this region, which is known for large short-term forecast errors due to analysis errors (e.g., McMurdie and Mass 2004). Torn and Hakim (2008) demonstrate how ensemble sensitivity analysis can be applied to determine the sensitivity of forecasts to the observations using output from this system. Gridded datasets such as those from the UW EnKF described here may prove useful for predictability and dynamics studies where flow-dependent analysis errors are important.

Acknowledgments. We thank Chris Velden and Dave Stettner for providing cloud wind data, Prof. Clifford Mass (University of Washington) for furnishing access to operational model data, and Chris Snyder (NCAR) for stimulating discussions. Two anonymous reviewers provided helpful suggestions for improving this manuscript. This study was made possible in part by the data made available to the NOAA Earth System Research Laboratory/Global Systems Division by the following commercial airlines: American, Delta, Federal Express, Northwest, United, and United Parcel Service. This research was sponsored by NSF Grant ITR-0205648, NOAA CSTAR Grant NA17RJ1232, and ONR Grant N00014-06-1-0510.

\section{APPENDIX A}

\section{Model Configuration}

For consistency, we use the same version of WRF and model settings over the 2 -yr period. This implementation uses the WRF three-class microphysics scheme (Hong et al. 2004), Kain-Fritsch cumulus parameterization (Kain and Fritsch 1990), MellorYamada-Janjic boundary layer scheme (Janjic 2001), and the Noah land surface model (Ek et al. 2003). We restrict forecasts to $24 \mathrm{~h}$ because beyond this lead time, features moving faster than $35 \mathrm{~m} \mathrm{~s}^{-1}$ (the average speed of Northern Hemisphere Rossby wave packets; Hakim 2003) would be located outside the lateral boundaries in the analysis.

As of 1 January 2005, a 90-member global ensemble did not exist; thus, in order to have an ensemble of lateral boundary conditions, we use one of the alternative methods proposed by Torn et al. (2006). In the fixed covariance perturbation method, perturbations consistent with a fixed-error covariance model are added to the ensemble-mean forecast on the lateral boundaries. The boundary perturbations used here are generated by sampling from the National Centers for Environmental Prediction (NCEP) covariance model contained in the WRF VAR system (Barker et al. 2004).

These randomly generated perturbations do not have temporal continuity, which could lead to shocks along the domain edges. To partially account for this, Torn et al. (2006) assume that the boundary perturbations evolve as an autoregressive process [their Eq. (4)]. The autocorrelation coefficient for a 6-h forecast (0.4) is taken from Torn et al. (2006), who determined this value from experiments using nested grids within larger domains. The perturbation scaling factor for 6-h forecasts (1.6) is set such that the variance of the perturbations is consistent with the error in the ensemble-mean forecast. We estimated the scaling factor by computing the ratio of the RMS error in 6-h NCEP Global Forecasting System (GFS) forecasts on this domain to the standard deviation of the WRF VAR perturbations. Moreover, the perturbation scaling factor for the 24-h forecast is determined in a similar manner, except that we compute the RMS error in 24-h GFS forecasts.

\section{APPENDIX B}

\section{Data Assimilation Specifics}

We only consider conventional in situ observations because the observation operators are simple (i.e., bilinear interpolation). Satellite radiances, which make 
up a large fraction of the observations assimilated by operational systems, are not considered here because of complexities arising from bias corrections and the expense of radiative transfer calculations. Figure 1 shows that the southern and western portions of this domain contain few surface and rawinsonde observations. Whereas ACARS observations are along flight tracks and near major airports, cloud winds are exclusively over the ocean and are most often found in climatologically cloudy regions (not shown). The larger ACARS observation count at 1800 and 0000 UTC results from more frequent takeoffs and landings near many of the airports along the west coast of North America.

To reduce the number of observations and remove observations that may not sample the atmosphere on scales resolved by the model, observations are preprocessed prior to assimilation. The coarse horizontal resolution of this domain does not allow for an accurate depiction of the horizontally narrow valleys in this region, thus, we only consider surface observations from stations whose elevation is within $300 \mathrm{~m}$ of the model topography. For domains with coarse horizontal grid spacing, temperature and wind observations from landbased stations often contain large representativeness errors and are not assimilated here. ACARS observations within $1 \mathrm{~h}$ of the analysis time are thinned by averaging all observations within one horizontal grid point and $25 \mathrm{hPa}$ of each other. This procedure is used to reduce the redundant information in the multiple takeoffs and landing reports in the area surrounding major airports. Errors in individual cloud motion vectors are often quite large and can be spatially correlated (e.g., Bormann et al. 2003); therefore, cloud wind observations are also "superobed" by averaging all observations within $1^{\circ}$ of latitude and longitude and $25 \mathrm{hPa}$ of each other.

Observations are quality controlled by comparing the innovation in the ensemble-mean $\left[y-\mathcal{H}\left(\overline{\mathbf{x}}^{b}\right)\right.$, where $y$ is the observation value, $\mathcal{H}$ is the observation operator that maps from model space to observation space, and $\overline{\mathbf{x}}^{b}$ is the 6-h ensemble-mean forecast state vector], with the standard deviation of the innovation variance $\left(\mathbf{H} \mathbf{P}^{b} \mathbf{H}^{\mathrm{T}}+\mathbf{R}\right.$, where $\mathbf{P}^{b}$ is the background error covariance matrix, $\mathbf{H}$ is the linearization of $\mathcal{H}$, and $\mathbf{R}$ is the observation error covariance matrix). If the innovation is more than 4 times the innovation standard deviation, the observation is assumed to be erroneous and is not assimilated.

Covariance estimates from finite-sized ensemble are prone to sampling errors, which are partially overcome by multiplying the covariance values by a localization function that goes to zero at some finite distance. In general, the covariance localization cutoff radius is a function of the horizontal grid spacing and the number of ensemble members (e.g., Hamill et al. 2001). Through trial-and-error testing, Dirren et al. (2007) found a radius of $2000 \mathrm{~km}$ to be the optimal trade-off between the desire to have a short enough radius to avoid far-field sampling errors in a 90-member ensemble and a long enough radius to avoid shocks in the model. Although vertical localization has been used in other applications of the EnKF (e.g., Whitaker et al. 2008), vertical localization is not employed here because it can produce severe shocks to the WRF model, possibly due to WRF's vertical coordinate (Dirren et al. 2007).

Covariance localization alone cannot completely overcome the effect of undersampling due to using a small ensemble, thus the deviations from the ensemblemean are artificially boosted at each assimilation time. If covariance inflation is not applied, the ensemble can lose variance with time and become overconfident in its estimate of the state. The ensemble variance is augmented at each assimilation time using the covariance relaxation technique described by Zhang et al. (2004) where each ensemble member's deviation from the ensemble-mean analysis is replaced by a weighted average of the deviations before and after data assimilation via

$$
\mathbf{x}_{a}^{\prime} \leftarrow(1-\alpha) \mathbf{x}_{a}^{\prime}+\alpha \mathbf{x}_{b}^{\prime},
$$

where $\mathbf{x}_{a}^{\prime}$ is an analysis member's deviation from the ensemble mean, $\mathbf{x}_{b}^{\prime}$ is a background forecast member's deviation from the ensemble mean, and $\alpha$ is the weighting factor given to the background perturbations. The weighting for background perturbations $(0.8)$ is determined by cycling a comparable WRF EnKF system on the same domain during October 2004. For the optimal value of $\alpha$, the error in the ensemble mean should match the spread of the ensemble, which is determined using the diagnostics described in section 3. Covariance relaxation is particularly advantageous on this domain due to the inhomogeneous observation distribution; in regions of dense (sparse) observations, the variance of the ensemble will be increased more (less). We also ran several experiments during the October 2004 where each ensemble member's deviation from the mean was multiplied by a constant (1.2) prior to assimilation (Anderson 2001). In these multiplicative inflation simulations, a majority of the ensemble members crashed after 2 weeks of observation cycling. The southwest corner of this domain is characterized by weak flow due to its proximity to the mean subtropical high pressure system, so that the ensemble spread was inflated to unreasonable values due to the lack of observations and choice of inflation. Barker (2005) found similar results 
when applying multiplicative inflation for an EnKF system near Antarctica.

\section{REFERENCES}

Anderson, J. L., 2001: An ensemble adjustment Kalman filter for data assimilation. Mon. Wea. Rev., 129, 2884-2903.

_ B. B. Wyman, S. Q. Zhang, and T. Hoar, 2005: Assimilation of surface pressure observations using an ensemble filter in an idealized global atmospheric prediction system. J. Atmos. Sci., 62, 2925-2938.

Barker, D. M., 2005: Southern high-latitude ensemble data assimilation in the Antarctic Mesoscale Prediction System. Mon. Wea. Rev., 133, 3431-3449.

—, W. Huang, Y. R. Guo, A. J. Bourgeois, and Q. N. Xiao, 2004: A three-dimensional variational data assimilation system for MM5: Implementation and initial results. Mon. Wea. Rev., 132, 897-914.

Bormann, N., S. Saarinen, G. Kelly, and J.-N. Thepaut, 2003: The spatial structure of observation errors in atmospheric motion vectors from geostationary satellite data. Mon. Wea. Rev., 131, 706-718.

Caya, A., J. Sun, and C. Snyder, 2005: A comparison between the 4DVAR and the ensemble Kalman filter techniques for radar data assimilation. Mon. Wea. Rev., 133, 3081-3094.

Dirren, S., R. D. Torn, and G. J. Hakim, 2007: A data assimilation case-study using a limited-area ensemble Kalman filter. Mon. Wea. Rev., 135, 1455-1473.

Dowell, D. C., F. Zhang, L. J. Wicker, C. Snyder, and N. A. Crook, 2004: Wind and temperature retrievals in the 17 May 1981 Arcadia, Oklahoma, supercell: Ensemble Kalman filter experiments. Mon. Wea. Rev., 132, 1982-2005.

Eckel, F. A., and C. F. Mass, 2005: Aspects of effective mesoscale, short-range ensemble forecasting. Wea. Forecasting, 20, 328 350.

Ek, M. B., K. E. Mitchell, Y. Lin, E. Rogers, P. Grunmann, V. Koren, G. Gayno, and J. D. Tarpley, 2003: Implementation of Noah land surface model advances in the National Centers for Environmental Prediction operational mesoscale Eta model. J. Geophys. Res., 108, 8851, doi:10.1029/ 2002JD003296.

Errico, R. M., and D. P. Baumhefner, 1987: Predictability experiments using a high resolution limited-area model. Mon. Wea. Rev., 115, 488-504.

Evensen, G., 2003: The ensemble Kalman filter: Theoretical formulation and practical implementation. Ocean Dyn., 53, 343 367.

Gaspari, G., and S. E. Cohn, 1999: Construction of correlation functions in two and three dimensions. Quart. J. Roy. Meteor. Soc., 125, 723-757.

Hakim, G. J., 2003: Developing wave packets in the North Pacific storm track. Mon. Wea. Rev., 131, 2824-2837.

Hamill, T. M., 2001: Interpretation of rank histograms for verifying ensemble forecasts. Mon. Wea. Rev., 129, 550-560.

— , 2005: Ensemble-based atmospheric data assimilation: A tutorial. Predictability of Weather and Climate, T. Palmer and R. Hagedorn, Eds., Cambridge Press, 124-156.

— J. S. Whitaker, and C. Snyder, 2001: Distance-dependent filtering of background error covariance estimates in an ensemble Kalman filter. Mon. Wea. Rev., 129, 2776-2790.

Hong, S. Y., J. Dudhia, and S. H. Chen, 2004: A revised approach to ice microphysical processes for the bulk parameterization of clouds and precipitation. Mon. Wea. Rev., 132, 103-120.
Houtekamer, P. L., H. L. Mitchell, G. Pellerin, M. Buehner, M. Charron, L. Spacek, and B. Hansen, 2005: Atmospheric data assimilation with an ensemble Kalman filter: Results with real observations. Mon. Wea. Rev., 133, 604-620.

Janjic, Z. I., 2001: Nonsingular implementation of the MellorYamada level 2.5 scheme in the NCEP Meso model. Tech. Rep. NCEP Office Note 437, National Centers for Environmental Prediction, Camp Springs, MD, 61 pp.

Kain, J. S., and J. M. Fritsch, 1990: A one-dimensional entraining detraining plume model and its application in convective parameterization. J. Atmos. Sci., 47, 2784-2802.

Knippertz, P., and J. E. Martin, 2007: A Pacific moisture conveyor belt and its relationship to a significant precipitation event in the semiarid southwestern United States. Wea. Forecasting, 22, 125-144.

Lorenz, E. N., 1982: Atmospheric predictability experiments with a large numerical model. Tellus, 34, 505-513.

McMurdie, L., and C. Mass, 2004: Major numerical forecast failures over the northeast Pacific. Wea. Forecasting, 19, 338 356.

Meng, Z., and F. Zhang, 2007: Test of an ensemble Kalman filter for mesoscale and regional-scale data assimilation. Part II: Imperfect model experiments. Mon. Wea. Rev., 135, 14031423.

Nutter, P., M. Xue, and D. Stensrud, 2004: Application of lateral boundary condition perturbations to help restore dispersion in limited-area ensemble forecasts. Mon. Wea. Rev., 132, 2378-2390.

Ralph, F. M., P. J. Nieman, and G. A. Wick, 2004: Satellite and CALJET aircraft observations of atmospheric rivers over the eastern North Pacific Ocean during the winter of 1997/98. Mon. Wea. Rev., 132, 1721-1745.

Skamarock, W. C., J. B. Klemp, J. Dudhia, D. O. Gill, D. M. Barker, W. Wang, and J. G. Powers, 2005: A description of the Advanced Research WRF version 2. Tech. Rep. $468+$ STR, National Center for Atmospheric Research, Boulder, CO, 88 pp.

Snyder, C., and T. M. Hamill, 2000: A hybrid ensemble Kalman filter-3D variational analysis scheme. Mon. Wea. Rev., 128, 2905-2919.

— , and F. Zhang, 2003: Assimilation of simulated Doppler radar observations with an ensemble Kalman filter. Mon. Wea. Rev., 131, 1663-1677.

Sutton, C., T. M. Hamill, and T. T. Warner, 2006: Will perturbing soil moisture improve warm-season ensemble forecasts? A proof of concept. Mon. Wea. Rev., 134, 3174-3189.

Szunyogh, I., E. J. Kostelich, G. Gyarmati, E. Kalnay, B. R. Hunt, E. Ott, E. Satterfield, and J. A. Yorke, 2008: A local ensemble transform Kalman filter data assimilation system for the NCEP global model. Tellus, 60, 113-130.

Tong, M. J., and M. Xue, 2005: Ensemble Kalman filter assimilation of Doppler radar data with a compressible nonhydrostatic model: OSS experiments. Mon. Wea. Rev., 133, 17891807.

Torn, R. D., and G. J. Hakim, 2008: Ensemble-based sensitivity analysis. Mon. Wea. Rev., 136, 663-677.

$\longrightarrow,-$, and C. Snyder, 2006: Boundary conditions for limitedarea ensemble Kalman filters. Mon. Wea. Rev., 134, 2490 2502.

Velden, C., and Coauthors, 2005: Recent innovations in deriving tropospheric winds from meteorological satellites. Bull. Amer. Meteor. Soc., 86, 205-223.

Whitaker, J. S., and T. M. Hamill, 2002: Ensemble data assimila- 
tion without perturbed observations. Mon. Wea. Rev., 130, 1913-1924.

_, G. P. Compo, X. Wei, and T. M. Hamill, 2004: Reanalysis without radiosondes using ensemble data assimilation. Mon. Wea. Rev., 132, 1190-1200.

—, T. M. Hamill, X. Wei, Y. Song, and Z. Toth, 2008: Ensemble data assimilation with the NCEP Global Forecast System. Mon. Wea. Rev., 136, 463-482.
Zhang, F., C. Snyder, and J. Sun, 2004: Impacts of initial estimate and observation availability on convective-scale data assimilation with an ensemble Kalman filter. Mon. Wea. Rev., 132, 1238-1253.

_ Z Z. Meng, and A. Aksoy, 2006: Test of an ensemble Kalman filter for mesoscale and regional-scale data assimilation. Part I: Perfect model experiments. Mon. Wea. Rev., 134, 722736. 